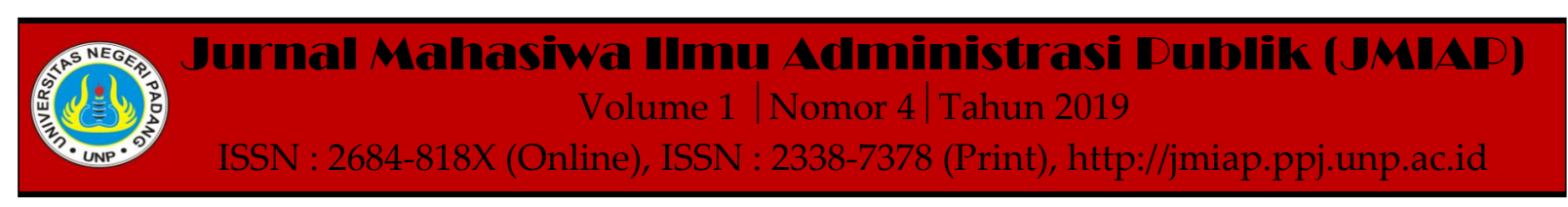

\title{
PENGARUH MODAL SOSIAL TERHADAP KESIAPSIAGAAN BENCANA DI KAWASAN PESISIR PANTAI AIR MANIS KOTA PADANG
}

\author{
Husnul Ramadhan ${ }^{1(a)}$, M. Fachri Adnan ${ }^{2(b)}$, Zikri Alhadi ${ }^{3(c)}$ \\ ${ }^{1}$ Jurusan Ilmu Administrasi Negara, Universitas Negeri Padang \\ ${ }^{2}$ Jurusan Ilmu Administrasi Negara, Universitas Negeri Padang \\ ${ }^{3}$ Jurusan Ilmu Administrasi Negara, Universitas Negeri Padang \\ ${ }^{a)}$ hsnlramadhan@gmail.com, ${ }^{b)}$ fachriadnan@fis.unp.ac.id, ${ }^{c)}$ zikrialhadi@fis.unp.ac.id
}

\begin{abstract}
This research is writen to know the positive relation between social capital and preperadnes disaster. The independent variabel used in this research is modal sosial and dependen variabel is preperadnes disaster. The subject in this research is civiel society at the Air Manis coast. Method of collecting data that is used in this research is quitioner with likert scale. All of the data that the authour get is analyzed by statiscal SPSS 17.0. quantitative data is analized by product moment analisis technique. The result show that there is positive realtion between social capital and preperadnes disaster in civiel society at the Air Manis coast. The result of data analisis corelation coefficient is $59.3 \%$. That mean is have positive relation between social capital and preperadnes disaster. Wich higher the social capital of civiel society is higher preperadnes disaster. It also mean that the lower social capital of civiel society is lower preperadnes disaster.
\end{abstract}

Keywords : Social Capital, Preperadnes Disaster

Corresponding author. Email.hsnlramadhan@gmail.com,fachriadnan@fis.unp.ac.id,

zikrialhadi@fis.unp.ac.id

How to cite this article. Ramadhan, R; Adnan, M. Fachri \& Alhadi, Zikri. (2019). Pengaruh Modal Sosial terhadap Kesiapsiagaan Bencana di Kawasan Pesisir Pantai Air Manis Kota Padang. Jurnal Mahasiwa Ilmu Administrasi Publik (JMIAP) Jurusan Ilmu Administrasi Negara Fakultas Ilmu Sosial Universitas Negeri Padang, Volume 1 (4), Hal. 110-118.

http://jmiap.ppj.unp.ac.id

ISSN : 2684-818X (Online), ISSN : 2338-7378 (Print)

Copyright $\bigcirc 2019$. Published by Pusat Kajian-Pemberdayaan dan Pelayanan Masyarakat (PK-P2M) FIS UNP Padang 


\section{PENDAHULUAN}

Kota Padang merupakan ibu Kota Provinsi Sumatera Barat dengan luas wiayah $694,96 \mathrm{~km}^{2}$ dan jumlah penduduk 902.413 jiwa. Berdasrakan data BPS (Badan Pusat Statistik) tahun 2016 menjadikan Kota Padang sebagai kota dengan penduduk terbanyak di Sumatera Barat. Berdasarkan analisis resiko bencana yang dilakukan oleh BPBD (Badan Penanggulangan Bencana Daerah) Kota Padang, terdapat 10 jenis potensi bahaya bencana yang menghantui Kota Padang dilihat dari kurun waktu 2002-2012, diantaranya 6 jenis bencana sudah terjadi dan 4 jenis ancaman bencana lainnya belum terjadi dalam kurun waktu 10 tahun terahir. Bencana gempa bumi yang terjadi tahun 2004, 2007, 2009 dan 2016 serta banjir yang terjadi hampir setiap tahun mengalami peningkatan dalam sepuluh tahun terahir, hal ini tentu menjadi perhatian khusus bagi pemrintah Kota Padang dan catatan bagi masyarakat untuk meningkatkan kesiapsiagaan bencana.

Sebagai salah satu kota yang memiliki potensi bencana tinggi maka pada tahun 2017 Kota Padang menetapkan Padang cerdas bencana dengan upaya membangun budaya kesiapsiagaan serta meningkatkan pengetahuan masyarakat terkait pengurangan resiko bencana (PRB) dengan melibatkan semua unsur seperti lembaga pemerintahan, pendidikan, masyarakat, dan dunia usaha.

Dalam perkembangan paradigma kebencanaan menghadirkan modal sosial sebagai salah satu upaya meminimalisir dampak bencana. Modal sosial dapat menjadi modal kuat yang dibangun oleh masyarakat setempat dan organisasiorgnaisasi yang ada karena masyarakat didaerah rawan bencana biasanya beradaptasi dengan situasi dengan mengembangkan jenis strategi bertahan hidup berdasakan pada sumber daya yang mereka miliki termasuk modal sosial.
Kelurahan Air Manis terbentang sepanjang pesisir pantai Air Manis, Sejak dimulainya pembangunan jalan pada tahun tahun 1987 ke Air Manis untuk menunjang pengembangan obyek wisata menjadikan kelurahan air manis sebagai salah satu tujuan wisata yang ramai di kunjungi. Selain memiliki pantai yang indah Kelurahan Air Manis juga memiliki daerah perbukitan, kondisi alam ini dimanfaat sebagai shelter alami ketika terjadi isu bencana tsunami.

Mayoritas masyarakat di Kelurahan Air Manis masih beranggapan bahwa bencana sebagai tindakan tuhan (Act of god) ketika tuhan yang berkehendak maka tidak ada manusia yang mampu untuk menolak, sehingga untuk mengurangi resiko terjadinya bencana maka masyarakat setempat melakukan ritual keagamaan yang disebut dengan do'a tolak bala.

Secara kultural masyarakat di Kelurahan Air Manis memiliki tradisi atau kebudayaan yang masih bertahan sampai sekarang, tradisi itu seperti do'a tolak bala dilakukan setiap rabaa akhir, dan biasanya dilakukan setahuan sekali dengan penghitungan kalender hijriyah. Ritual ini ditujukan untuk memohon kepada tuhan agar tidak di datangkan bencana di daerah mereka.

Di Kelurahan Air Manis sendiri memiliki modal sosial yang telah melekat ditengah masyarakat seperti kepercayaan sosial yang tinggi karena mayoritas masyarakat sudah saling mengenal dan menetap dalam jangka waktu yang lama. Norma yang berlaku ditengah masyarakat seperti "anak dipangku kamanakan di bimbiang" yang dapat dimaknai sebagi tanggung jawab seorang mamak terhadap anak dan kamanakannya, nilai gotong royong dan tradisi tolak bala. Jaringan sosial yang terbentuk di kelurahan Air Manis Serti arisan ibu PKK, komunitas senam pagi lansia, karang taruna, ikatan kepemudaan dan wiritan remaja masjid menjadi modal sosial yang kuat yang berada di tengah masyarakat. 
Berdasarkan uraian tersebut maka dalam penelitian ini terdapat dua macam hipotesa yaitu: H0 terdapat pengaruh modal sosial terhadap kesiapsiagaan bencan di kawasan pesisir pantai Air Manis Kota Padang, dan Ha tidak terdapat pengaruh antara modal sosial terhadap kesiapsiagaan bencana di kawasan Air Manis Kota Padang, sehingga artikel ini bertujuan untuk mengetahui pengaruh modal sosial terhadap kesiapsiagaan bencana di kawasan pesisir pantai Air Manis Kota Padang.

\section{TINJAUAN PUSTAKA \\ Modal Sosial}

Menurut R. Putnam modal sosial adalah bagian dari kehidupan sosial seperti jaringan, norma dan kepercayaan yang mendorong partisipan bertindak bersama secara lebih efektif untuk mencapai tujuantujuan bersama. (Jhon field.2011:51).

Sementar itu Eva cox mendefenisikan modal sosial sebagai rangkaian hubungan antar manusia yang ditopang oleh jaringan, norma dan kepercayaan sosial yang memungkinkan efesiensi dan efektifitasnya koordinasi dan kerja sama untuk menghasilkan keuntungan dan kebaikan bersama. (Rijanta.2015.112).

Dari pendapat Ahli tersebut dapat dipahami bahwa unsur modal sosial terdiri dari kepercayaan sosial, norma dan jaringan. Tiga ramuan ini dapat dipakai untuk melihat gambaran modal sosial yang ada di tengah masyarakat.

\section{1) Kepercayaan sosial (trust)}

Dasar perilaku manusia dalam membangun modal sosial adalah rasa percaya. Kasih sayang dalam keluarga dilandasi oleh rasa saling percaya antar individu, rasa percaya menjadi alat untuk membangun hubungan. Rasa percaya merupakan sikap yang siap menerima resiko dan ketidakpastian dalam berinteraksi. Sehingga kepercayaan sosial dapat dimaknai sebagai Keinginan mengambil suatu resiko dalam hubungan sosial dan didasari oleh perasaan yakin.
Pada daerah dengan ras dan komposisi populasi yang homogen serta tingkat ketidaksamaan yang rendah akan memberikan tingkat rasa percaya yang tinggi. Umumnya orang akan lebih mempercayai keluarga sendiri, dari pada orang lain, atau akan lebih mempercayai teman dari pada orang lain, atau lebih mempercayai orang satu kampung dari pada orang lain. Kepercayaan sosial didapatkan dari proses interaksi sosial. Ketuhanan, etika, dan hukum merupakan sumber utama dari rasa percaya, sedangkan penyusunan kelembagaan dan kekeluargaan menjadi bentuk struktural dari rasa percaya.

\section{2) Norma}

Norma merupakan aturan yang harus dipatuhi dan diikuti oleh masyarakat dalam etnis tertentu yang digunakan untuk menentukan kuat tidaknya hubungan antara individu yang satu dengan individu lainnya. Norma merupakan nilai universal yang mengatur perilaku individu dalam suatu masyarakat atau kelompok. Fukuyama (1999) menyatakan modal sosial sebagai norma informal yang bersifat instan dan dapat membangun kerjasama antar dua atau lebih individu. Norma sebagai bagian dari modal sosial dapat dibangun dari norma/etika yang disepakati antar teman. Selanjutnya dapat dikatakan bahwa, rasa percaya, norma dan komunitas sosial yang terbentuk sangat berkaitan dengan modal sosial. Bagi masyarakat minang kabau misalnya dengan falsafah adat basandi syarak, syarak basandi kitabullah, maka norma adat merujuk pada norma agama sehingga norma adat dan norma agama saling berkaitan antara satu sama lainnya.

\section{3) Jaringan sosial (link)}

Jaringan merupakan system pada saluran komunikasi untuk mengembangkan dan menjaga hubungan interpersonal. Rasa percaya dan nilai-nilai yang dianut bersama (norma) juga berperan pada keinginan untuk bergabung membentuk jaringan dengan orang lain. Jaringan terbentuk ketika terjadi interaksi antar satu orang atau 
lebih, umumnya jaringan terbentuk dalam dan antar organisasi atau komunitas.

Interaksi yang baik dapat menjadi jaringan, pada dasarnya jaringan terbentuk karena hubungan simbiosis mutualisme hubungan yang saling menguntungkan bagi kedua pihak yang sedang berinteraksi, merawat jaringan akan memperkuat mudal sosial itu sendiri.

\section{Kesiapsiagaan Bencana}

Secara umum UN-OCHA memberikan penjelasan bahwa kesiapsiagaan adalah aktivitas pra-bencana yang dilaksanakan dalam konteks manajemen risiko bencana dan berdasarkan analisa risiko yang baik, hal ini mencakup pengembangan /peningkatan keseluruhan strategi kesiapan, kebijakan, struktur institusional, peringatan dan kemampuan meramalkan, serta rencana yang menentukan langkah-langkah yang tepat.

Gilespie dan Streeter mendefenisikan kesiapsiagaan sebagai perencanaan, identifikasi sumber daya, system peringatan, pelatihan, simulasi, dan tindakan prabencana yang diambil untuk tujuan utama meningkatkan keamaan dan efektifitas respon masyarakat masyarakat selama bencana. (Beovola 2014:24).

\section{METODE PENELITIAN}

Penelitian ini dilakukan di kawasan pesisir pantai kelurahan Air Manis Kota Padang. Penelitian ini merupakan penelitian kuantitatif dengan metode deskriptif. Jenis Penelitian ini adalah penelitian asosiatif yang bertujuan untuk mengetahui hubungan antar dua variabel atau lebih. pengambilan data dalam penetian ini menggunakan quisioner atau angket, dengan skala likert.

Sesuai dengan judul dalam penelitian ini maka yang menjadi populasi dalam penelitian ini adalah masyarakat di Kelurahan Air Manis dengan jumlah populasi sebanyak 458 kepala keluarga, Dari 458 kepala keluarga yang terdapat di Kelurahan Air Manis, maka penelitian ini di fokuskan kepada penduduk yang rumahnya berada di kawsan pesisir pantai, jumlah kepala keluarga (KK) yang berada di kawasan pesisir pantai adalah 150 kepala keluarga.

Sampel dalam penelitian ini adalah masyarakat yang menetap dikawasan pesisir pantai Air Manis, Berdasarkan rumus Slovin maka jumlah sampel didapatkan sebanyak 110 orang. Data dalam penelitian ini adalah data interval yang bersumber dari data primer dan data sekunder.

Teknik analisis data dalam penelitian ini menggunakan perhitungan komputasi program SPSS (Statistis product and service solution) versi 17. Analisis data dalam penelitian ini melalui beberapa tahapan, mulai dari tahapan analisi deskriptif, uji asumsi klasik, uji regresi linear sederhana, dan pengujian hipotesa.

\section{HASIL DAN PEMBAHASAN}

Hasil pengolahan data dari penelitian ini dapat dilihat dari tabel berikut:

Tabel 1. Hasil Kontribusi (R) Pengaruh Variabel Modal Sosial Terhadap Kesiapsiagaan

Bencana

Model Summary

\begin{tabular}{lcccc}
\hline Model & $\mathrm{R}$ & $\mathrm{R}$ Square & $\begin{array}{c}\text { Adjusted R } \\
\text { Square }\end{array}$ & $\begin{array}{c}\text { Std. Error of the } \\
\text { Estimate }\end{array}$ \\
\hline $\begin{array}{l}.770^{\mathrm{a}} \\
\text { a. Predictors: (Constant), MODAL SOSIAL }\end{array}$ & .593 & .589 & 3.55474 \\
\hline \multicolumn{4}{l}{ Sumber: Diolah dari data primer } & 2019
\end{tabular}


Untuk melakukan interpertasi kekutan hubungan antara variabel bebas dan variabel terikat dilakukan dengan melihat angka koefisien korelasi, hasil perhitungan dengan menggunakan interpertasi nilai $r$ adalah sebagi berikut:

a) 0 : Tidak ada korela antara dua variabel

b) $>0-0.25:$ Korelasi sangat lemah

c) $>0.25-0.5$ : Korelasi cukup

d) > $0.5-0.75$ : Korelasi kuat

e) >0.75 - 0.99: Korelasi sangat kuat

f) $1:$ Korelasi sempurna

Berdasrkan hasil uji pada tabel 1. dapat dijelaskan bahwa besarnya nilai korelasi atau hubungan (R) yaitu sebesar 0.770. Nilai ini dapat diinterpertasikan bahwa hubungan kedua variabel berada pada kategori sangat kuat. dari output tersebut juga diperoleh hasil koefisien determinasi (R square) koefisien determinasi atau nilai $r$ square menunjukkan seberapa bagus model regresi yang dibentuk oleh interaksi variabel bebas dan variabel terikat. Hasil nilai $r$ square dari tabel diatas adalah sebesar 0.593, sehingga dapat ditafsirkan bahwa variabel bebas (modal sosial) memiliki pengaruh kontribusi sebesar 59.3\% terhadap variabel terikat (kesiapsiagaan bencana).

Tabel 2. Uji Nilai Signifikan

\begin{tabular}{|c|c|c|c|c|c|c|}
\hline \multicolumn{7}{|c|}{ ANOVA $^{b}$} \\
\hline Model & & Sum of Squares & df & Mean Square & $\mathrm{F}$ & Sig. \\
\hline \multirow[t]{3}{*}{1} & Regression & 1988.715 & 1 & 1988.715 & 157.383 & $.000^{\mathrm{a}}$ \\
\hline & Residual & 1364.703 & 108 & 12.636 & & \\
\hline & Total & 3353.418 & 109 & & & \\
\hline
\end{tabular}

a. Predictors: (Constant), Modal Sosial

b. Dependent Variable: Kesiapsiagaan bencana

\section{Sumber : Hasil pengolahan data primer 2019}

Tabel uji signifikan diatas, digunakan untuk menentukan taraf signifikansi atau linearitas dari regresi. Kriteria dapat ditentukan berdasarkan uji nilai signifikansi (Sig), dengan ketentuan jika nilai Sig < 0.05. Berdasarkan tabel diatas diperoleh nilai Sig. $=0.000$ berarti nilai Sig. $<$ dari kriteria signifikan (0.05). Dengan demikian model persamaan regresi berdasarkan data penelitian adalah signifikan, atau model persamaan regresi memenuhi kriteria.

Setelah diketahui hasil kontribusinya selanjutnya dilihat coefficients variabel modal sosial terhadap kesiapsiagaan bencana, uji koefisien dapat dilihat pada tabel berikut.

Tabel 3. Uji Coefficients Regresi Sederhana

\begin{tabular}{|c|c|c|c|c|c|c|}
\hline \multicolumn{7}{|c|}{ Coefficients $^{a}$} \\
\hline \multirow[b]{2}{*}{ Model } & & \multicolumn{2}{|c|}{ Unstandardized Coefficients } & \multirow{2}{*}{$\begin{array}{c}\begin{array}{c}\text { Standardized } \\
\text { Coefficients }\end{array} \\
\text { Beta }\end{array}$} & \multirow[b]{2}{*}{$\mathrm{t}$} & \multirow[b]{2}{*}{ Sig. } \\
\hline & & B & Std. Error & & & \\
\hline \multirow[t]{2}{*}{1} & (Constant) & 6.525 & 3.001 & & 2.174 & .032 \\
\hline & MODAL SOSIAL & 1.158 & .092 & .770 & 12.545 & .000 \\
\hline
\end{tabular}

a. Dependent Variable: KESIAPSIAGAAN BENCANA

Sumber: Diolah dari data primer 2019 
Hasil perhitungan koefisien regresi sederhana diatas memperlihatkan nilai koefisien contant (a) sebesar 6.525 sedangkan nilai modal sosial (b / koefisien regresi) sebesar 1.158, sehingga persamaan regresinya dapat ditulis sebagai berikut:

$$
\begin{aligned}
& Y=a+b X \\
& Y=(6.525+1.158 X)
\end{aligned}
$$

Persamaan tersebut dapat dijelaskan bahwa konstanta sebesar 6.525 mengandung arti bahwa nilai konsistensi variabel kesiapsiagaan bencana adalah sebesar 6.525. Selanjutnya koefisien regresi tersebut bernilai positif (1.158),yang terdapat pada koefisien regresi variabel bebas (modal sosial) menggambarkan bahwa hubungan antara variabel bebas (modal sosial) dengan variabel terikat (kesiapsiagaan bencana) adalah searah, koefisien regresi modal sosial sebesar 1.158 menyatakan bahwa setiap penambahan $1 \%$ nilai modal sosial, maka nilai kesiapsiagaan bencana bertambah sebesar 1.158.

Dari hasil analisis regresi sederhana dapat disimpulkan bahwa antara variabel modal sosial dan variabel kesiapsiagaan bencana mempunyai hubungan yang sangat kuat karena nilai korelasi sebesar 0.770 .

Setelah dilakukan penelitian dan dialanjutkan dengan menganalisis data, maka hasil penelitian membuktikan bahwa modal sosial memiliki pengaruh secara signifikan terhadap kesiapsiagaan bencana di kawasan pesisir pantai Air Manis Kota Padang, dengan nilai signifikansi semua variabel lebih kecil dari 0.05 , besarnya pengaruh modal sosial terhadap kesiapsiaan bencana yaitu sebesar $59.3 \%$.

Gambar 1. pengaruh kontribusi variabel $X$ terhadap variabel $Y$

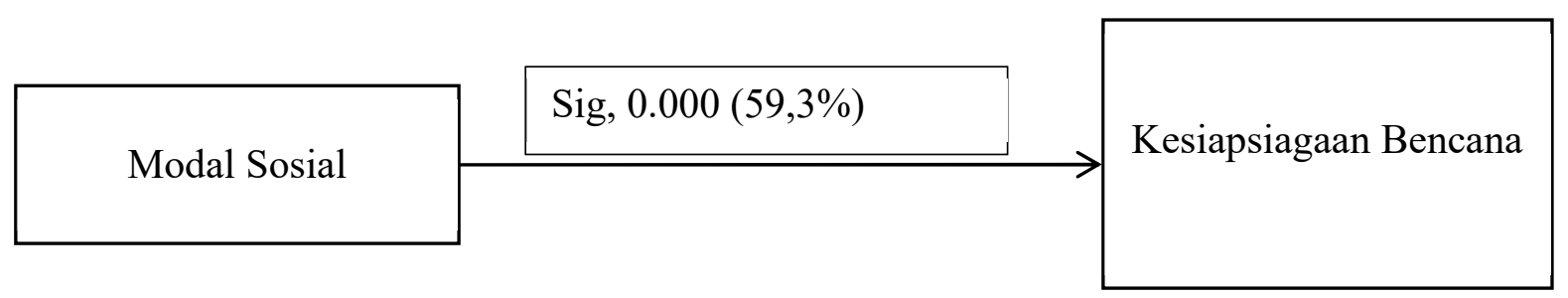

Sumber: Hasil pengolahan data 2019

Dari gambar diatas dapat diketahui bahwa kontribusi variabel modal sosial terhadap kesiapsiagaan bencana dengan model regresi yang telah memenuhi kriteria Sig. sebesar 0.000 dalah 59.3\%. Artinya modal sosial dapat menjadi faktor yang kuat dalam meningkatkan kesiapsiagaan bencana dikawasan pesisir pantai Air Manis.

Indikator yang dipakai untuk melihat modal sosial berdasarkan teori yang dikemukakan oleh R. Putnam yaitu: kepercayaan sosial, norma dan jaringan sosial. Di Kelurahan Air Manis kepercayaan sosial yang terjalin ditengah masyarakat dapat dikategorikan tinggi, hal ini dikarenakan mayoritas penduduk sudah menetap untuk waktu yang lama.
Norma sosial yang berlaku di kawasan pesisir pantai Air Manis juga dapat dikategorikan tinggi, dilihat dari jawaban responden untuk indikator norma nilai mean yang berada di atas 3.27 atau sebanyak 68 responden $(68 \%)$ dan berada pada rentang $61 \%$ - $80 \%$, yang tergolong dalam kategori tinggi. Angka tersebut menunjukkan bahwa menurut responden norma yang berlaku ditengah masyarakat tergolong kuat dalam meningkatkan kesiapsiagaan bencana.

Sayangnya jaringan sosial yang terbentuk di kawasan pesisir pantai Air Manis belum dimanfaatkan secara maksimal untuk meningkatkan kesiapsiagan bencana, hal ini dilihat dari 
nilai mean yang melebihi 3.18 sebanyak 30.75 yang mana jika dibulatkan menjadi 31 responden $(28 \%)$ menjawab faktor jaringan sosial kurang diperhatikan dalam meningkatkan kesiapsiagan bencana, angka tersebut berada pada rentang $21 \%-40 \%$, yang tergolong dalam kategori rendah. Keterlibatan komunitas yang ada dikawasan pesisir pantai Air Manis seperti arisan PKK, senam pagi lansia, karang taruna, ikatan pemuda dan wiritan remaja masjid belum dimanfaatkan secara maksimal untuk meningkatkan kesiapsiagaan bencana dikawasan pesisit pantai Air Manis Kota Padang.

Sehingga hasil penelitian ini menunjukkan bahwa hubungan variabel modal sosial terhadap kesiapsiagaan bencana sangat kuat, dimana setiap penambahan $1 \%$ modal sosial maka akan meningkatkan 1.158 nilai kesiapsiagan bencana dikawasan pesisir pantai Air Manis Kota Padang.

Hasil penelitian ini juga membuktikan teori dari yang di kemukakan oleh Robert Putnam (Jhon field.2011:51) yang mengemukakan bahwa modal sosial adalah bagian dari kehidupan sosial seperti jaringan, norma dan kepercayaan yang mendorong partisipan bertindak bersama secara lebih efektif untuk mencapai tujuantujuan bersama. Dalam hal ini modal sosial yang kuat tentu akan dapat mempengaruhi kesiapsiagaan bencana karena kesiapsiagaan bencana akan menjadi tujuan bersama bagi masyarakat yang berasa di kawasan yang rawan akan bencana. Hal ini menunjukkan bahwa terdapat pengaruh modal sosial terhadap kesiapsiagaan bencana.

Hasil penilitian ini membuktikan teori yang dikemukakan oleh Nakagawa dan Shaw yang mengatakan bahwa modal sosial adalah salah satu unsur yang hilang dalam manajemen bencana dalam menghadapi tsunami. Modal sosial yang kuat berarti tingkat kepercayaan masyarakat, norma yang berlaku dan relasi atau jaringan yang luas akan sangat membantu dalam manajemen bencana khususnya meningkatkan kesiapsiagaan bencana.

Hasil penelitian ini mendukung teori yang dikemukakan oleh Woolcock (Rijanta.2015:84) bahwa modal sosial merupakan mekanisme dan hubungan antar kepercayaan norma dan jaringan dalam pengaturan sosial di suatu daerah. Dari teori tersebut dapat dipahami bahwa mekanisme merupakan suatu kesatuan dalam hal ini berarti kesatuan antara kepercayaan, norma, jaringan dan pengaturan sosial tujuan dari mekanisme ini tidak lain ialah untuk mencapai tujuan bersama. hasil ini menunjukkan bahwa terdapat pengaruh modal sosial terhadap kesiapsiagaan bencana.

Hasil penelitian ini dapat membuktikan teori yang kemukakan oleh Gilespie dan Streeter (Beovola 2014:24) yang mengemukakan kesiapsiagaan sebagai perencanaan, identifikasi sumber daya, sistem peringatan, pelatihan, simulasi, dan tindakan prabencana yang diambil untuk tujuan utama meningkatkan keamaan dan efektifitas respon masyarakat masyarakat. Tujuan utama dari kesiapsiagaan ialah meningkatkan keamanan dan efektifitas respon masyarakat dalam menghadapi bencana itu sendiri sehingga dengan adanya modal sosial dalam manajemen bencana hal ini akan meningkatkan keamanan dan efektifitas respon masyarakat. Hal ini menunjukkan bahwa terdapat pengaruh modal sosial terhadap kesiapsiagaan bencana.

Penelitian ini juga mendukung teori yang dikemukakan oleh Drabek dan Hoetmar (beavaola. 2014: 26-27) bahwa enam prinsip dasar kesiapsiagaan bencana seperti kesiapsiagaan merupakan proses yang berkesinambungan, kesiapsiagaan mengurangi ketidak tahuan, kesiapsiagaan merupakan kegiatan pendidikan, kesiapsiagaan didasarkan pada pengetahuan, kesiapsiagaan menghasilkan tindakan yang tepat, resistensi terhadap 
bencana dan perencanaan yang jelas. dari teori tersebut dapat dipahami bahwa salah satu prinsip yang mendukung pengaruh modal sosial terhadap kesiapsiagaan bencana adalah kesiapsiagaan mengurangi ketidak tahuan, karena cara untuk mengurangi ketidak tahuan adalah memberi tahukan dan dalam hal ini diperlukan kepercayaan terhadap informasi dan penyampai informasi itu sendiri.

Dapat dikatakan dengan memanfaatkan modal sosial dalam manajemen bencana akan meningkatkan kesiapsiagaan masyarakat dalam menghadapi bencana. Dengan demikian dapat disarankan kepada masyarakat untuk mempertahankan modal sosial yang telah ada, hal ini tentunya perlu didukung dengan pelatihan dan penyuluhan terhadap kesiapsiagaan bencana tujuannya adalah agar modal sosial yang ada di tengah masyarakat dapat bertahan dan masyarakat mengalami peningkatan dalam hal kesiapsiagaan bencana. Karena modal sosial berbeda dengan modal-modal lainnya yang apabila digunakan maka akan mengurangi nilai dari modal itu sendiri, modal sosial justru akan mengurangi pengurangan nilai apabila tidak digunakan. Selanjutnya untuk mencapai tujuan itu tentunya perlu dorongan dan bantuan dari pemerintah. Upaya ini dilakukan agar dapat meningkatkan kesiapsiagaan masyarakat dalam mengahadapi bencana.

\section{PENUTUP}

Modal sosial dikawasan pesisir pantai Air Manis masih sangat kuat, hal ini dikarenakan mayoritas masyarakat sudah menetap untuk waktu yang lama sehingga kepercayaan sosial ditengah masyarakat sudah terjalin dengan erat, norma yaang berlaku di tengah masyarakat juga memeiliki kontribusi yang signifkitan terhadap kesiapsiagan masyarakat, seperti doa tolak bala, gotong royong dan peran mamak terhadap anak dan kemanakan untuk meningkatkan kesiapsiagaan bencana. Sayangnya jaringan sosial yang ada belum dimaksimalkan dengan baik untuk meningkatkan kesiapsiagan bencana, hal ini dapat dilihat dari jarangnya simulasi dan penyuluhan terkait kesiapsiagaan bencana yang dirasakan oleh masyarakat di kawasan peisir pantaui Air Manis.

Dari kesimpulan tersebut penulis menyarakan kepada masyarakat di kawasan pesisi pantai Air Manis untuk dapat membuka relasi dengan semua pihak, baik itu pemrintah, pihak swasta ataupun dari masyarakat itu sendiri untuk dapat meningkatkan kesiapsiagaan bencana. Kepada pemerintah penulis menyarankan untuk meningkatkan koordinasi antar instansi sehingga modal sosial yang terdapat di kawasan pesisir pantai Air Manis dapr termanfaatkan dengan baik untuk meningkatkan kesiapsiagan bencana.

\section{DAFTAR KEPUSTAKAAN}

Cut Husna. 2012. Faktor-Faktor Yang Mempengaruhi Kesiapsiagaan Bencana di RSUDZA.Banda Aceh. Idea Nursing Jurnal. (Volume 3 Nomor 2 tahun 2012).

Deny hidayati. 2008. Kesiapsiagaan Masyarakat: Paradigma Baru Pengelolaan Bencana Alam di Indonesia. Jurnal kependudukan Indonesia. (Volume III Nomor 1 tahun 2008).

Dina dan Titis. 2018.The Social Capital in Comunity Preparedness Towards The Landslide Disaster in Pagerharjo Kulunprogo. Jurnal KAWISTARA. (Volume 8 nomor 3 Desember 2018).

Febriana, dkk. 2015. Kesiapsiagaan Masyarakat Desa Siaga Bencana Dalam Menghadapi Bencana Gempa Bumi di Kecematan Meuraxa Kota Banda Aceh.Jurnal Ilmu Kebencanaan. (Volume 2 Nomor 3 Agustus 2015).

Field Jhon.2011. Modal Sosial. Kreasi Wacana. Bantul. 
Kusumasari Bevaola. 2014. Manajemen Bencana dan Kapabilitas Pemerintah Lokal. Gava Media. Yogyakarta.

Lawang Robert. 2005. Kapital Sosial dalam Prespektif Sosiologik suatu pengantar. FISIP UI Pers. Depok.

Nurjanah, dkk. 2012. Manajemen Bencana. Alfabeta. Bandung.

Rijanta R.dkk.2015.Modal Sosial Dalam Manajemen Bencana. Gadjah Mada University Pers. Yogyakarta.

Kusuma Wardani, dkk. 2012. Kajian Penguatan Kapasitas Masyarakat dalam Pengurangan Resiko Bencana Alam di Indonesia. Prosiding pemaparan hasil penelitian pusat penelitian geoteknologi LIPI.2012.

Melisa dan Erika.2014.Kepercayaan (Trust) terhadap pengurus organisasi dan komitmen aktif pada organisasi mahasiswa daerah di yogyakarta. Jurnal Psikologi Integratif. (Volume 2 Nomor 1 Juni 2014).

Rahmadian.2015.Evaluasi Kebijakan Peningkatan Kesiapsiagaan Masyarakat Kota Padang Dalam Menghadapi Bencana Gempa Bumi dan Tsunami.Jurnal Kajian Ilmu Administrasi Negara. (Volume 3 Nomor 2 Tahun 2015).

Rusdi. 2003. Modal Sosial: Konsep dan Aplikasi. jurnal masyarakat dan budaya. Volume 5 nomor 3 tahun 2003).

Suparman Abdullah. 2013. Potensi dan Kekuatan Modal Sosial Dalam Suatu Komunitas. Jurnal Socius.(Volume XII Nomor tahun 2013).

Wasisto Raharjo. 2013. Anilisis Penanggulangan Bencana Berbasis Prespektif Cultural Theory. Jurnal Penanggulangan Bencana. (Volume 4 Nomor 4 Juni 2013).
Zikri Alhadi dan Siska Sasmita. 2014. Kesiapsiagaan Masyarakat Kota Padang dalam Menghadapi Resiko Bencana Gempa dan Tsunami Berbasis Kearifan lokal (study terhadap resiko bencana).Jurnal Humanus. (Volume XIII Nomor.2 tahun 2014. 